See Article page 82.

\section{Commentary: Hanging in the air}

\author{
Oz M. Shapira, MD
}

Coronary artery anomalies (CAAs) are uncommon clinicopathologic entities. The management of CAAs is individualized and remains controversial due to insufficient data and a poor understanding of the pathophysiology in many patients. ${ }^{1}$

In this issue of the Journal, D'Angelo and colleagues ${ }^{2}$ describe a rare case of intractable angina induced by a kink in an aerialized distal segment of left anterior descending coronary artery (LAD). The defect was surgically repaired by obliterating the space underneath the aerialized segment and straightening the kink. As highlighted by the authors, the same technique might be useful for repair of an inadvertent perforation of the right ventricle. This is also an excellent technique for control of LAD arterial and venous side-branch bleeding without compromising LAD flow.

However, similar to many other CAAs, the considerations that led the authors to opt for surgical repair were not straightforward. The anomaly described in this case fits into the category of intrinsic coronary arterial anatomy anomalies. ${ }^{1}$ A more common entity in this category is intramural coronary artery (myocardial bridge). The clinical importance and management of this type of CAA is highly dependent on objective evidence of myocardial ischemia. The causal relationships between the anatomical finding and the clinical manifestation of angina in the current case is inconclusive. Objective evidence supporting an important cause-effect relationship includes the findings of a hypermobile LAD segment in coronary angiography, coupled with documentation of a reversible perfusion defect on positron emission tomography-computed tomography that normalized postoperatively in parallel to resolution of

\footnotetext{
From the Department of Cardiothoracic Surgery, Hadassah Hebrew University Medical Center, Jerusalem, Israel.

Disclosures: The author reported no conflicts of interest.

The Journal policy requires editors and reviewers to disclose conflicts of interest and to decline handling or reviewing manuscripts for which they may have a conflict of interest. The editors and reviewers of this article have no conflicts of interest.

Received for publication Aug 7, 2021; revisions received Aug 7, 2021; accepted for publication Aug 11, 2021; available ahead of print Aug 17, 2021.

Address for reprints: Oz M. Shapira, MD, Department of Cardiothoracic Surgery, Hadassah Hebrew University Medical Center, POB 12000, Ein Kerem, Jerusalem 91120, Israel (E-mail: oz.shapira@gmail.com).

JTCVS Techniques 2021;9:87-8

2666-2507

Copyright (c) 2021 The Author(s). Published by Elsevier Inc. on behalf of The American Association for Thoracic Surgery. This is an open access article under the CC BY-NC-ND license (http://creativecommons.org/licenses/by-nc-nd/4.0/).

https://doi.org/10.1016/j.xjtc.2021.08.020
}

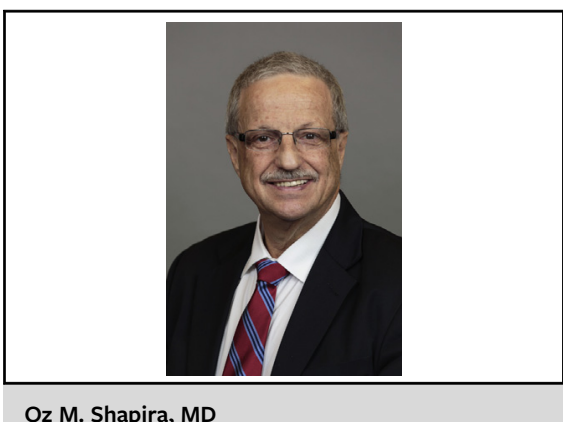

Oz M. Shapira, MD

CENTRAL MESSAGE

Angina induced by an aerialized coronary artery is rare. Surgical management is indicated in patients with objective evidence of large myocardial ischemia or those refractory to medical treatment.

angina. In contrast, lack of a significant LAD stenosis $(30 \%)$ in coronary angiography, and more importantly, inability to document the functional significance of the anomaly by the relative flow reserve test $(\mathrm{RFR}=0.91)$ are concerning. Straightening of the kinked segment by the RFR catheter might be a plausible explanation but leaves some doubt. The technical problem associated with the RFR testing could have been circumvented by performing stress cardiac magnetic resonance-an emerging noninvasive tool to evaluate myocardial perfusion. ${ }^{3}$

Once irrefutable objective evidence of ischemia is obtained, surgical repair should be reserved only for patients with life-threatening large areas of myocardial ischemia. The indication for surgery in cases similar to the current one (ischemia limited to the distal LAD territory) is appropriate in only a very small minority of patients who are truly refractory to optimal medical management and are low surgical risk.

The authors should be congratulated for performing an off-pump simple and reproducible surgical repair. However, the answers to the questions whether an aerialized coronary artery represents a true CAA, or merely a variant of the normal, and whether this anatomical variant can induce myocardial ischemia are still hanging in the air.

\section{References}

1. Angelini P, Velasco JA, Flamm S. Coronary anomalies. Incidence, pathophysiology and clinical relevance. Circulation. 2002;105:2449-54. 
2. D'Angelo AM, Rosner GF, Smith CR. Surgical repair of an aerialized coronary arterial segment causing myocardial ischemia. J Thorac Cardiovasc Surg Tech. 2021;9:82-4.
3. Agrawal HA, Wilkinson JC, Noel CV, Qureshi AM, Masand PM, Mery CM, et al. Impaired myocardial perfusion on stress CMR correlates with invasive FFR in children with coronary anomalies. J Invasive Cardiol. 2021;33:E45-51. 